OPEN ACCESS

Edited by:

Syed Mukhtar Ahmed, Vanderbilt University, United States

Reviewed by: Miriam Sullivan, Edith Cowan University, Australia Gavin Porter, Harvard Medical School, United States

*Correspondence: Nina M. Nesseth nesseth@sciencenorth.ca

Specialty section: This article was submitted to STEM Education, a section of the journal Frontiers in Education

Received: 02 March 2021 Accepted: 22 September 2021 Published: 29 October 2021

Citation:

Nesseth NM, Henson AM and Barriault CL (2021) A Framework for

Understanding the Nature of Questions Asked by Audience

Participants at Science Cafés.

Front. Educ. 6:674878.

doi: 10.3389/feduc.2021.674878

\section{A Framework for Understanding the Nature of Questions Asked by Audience Participants at Science Cafés}

\author{
Nina M. Nesseth ${ }^{1 *}$, Amy M. Henson ${ }^{1,2}$ and Chantal L. Barriault ${ }^{1}$ \\ ${ }^{1}$ Laurentian University, Sudbury, ON, Canada, ${ }^{2}$ Science North, Sudbury, ON, Canada
}

Science Cafés are events designed as public engagement tools that create the opportunity for open dialogue between members of the general public and experts on the issue being discussed at the event. This study explores the nature of questions being asked by audience participants during discussion sessions of Science Café events. It was conducted by coding audio recordings of audience participant engagements at 41 Science Café events held between 2010 and 2019. The result of this analysis produced a novel taxonomic framework to describe audience participant behaviors in terms of their learning goals. This framework was evaluated by applying it to samples of Science Café question data selected by Science Café topic theme. Comparisons between question-asking behaviors for specific Science Café topics and overall trends in questionasking behaviors for all Science Cafés revealed significant changes in audience participant learning goals when asking questions at Science Cafés centered on different topic types. Implications for understanding Science Café audiences and potential developments for Science Café events as public science engagement tools are discussed.

Keywords: science communication, dialogue, public engagement, informal learning, question asking, science café

\section{INTRODUCTION}

Science Cafés are events designed as public engagement tools that create the opportunity for open dialogue between members of the general public and experts on the issue being discussed at the event. Audience participants have the opportunity to direct questions or commentary to the panel and/or other event attendees during the discussion period of the event, which are then discussed by the panel and/or other audience members. To date, there has been little exploration of the nature of questions put forward for discussion at Science Café events. This study clarifies the nature of questions asked by audience participants at Science Café discussions in terms of the learning goals of those participants, with the aim of understanding the types of information being sought or exchanged by Science Café participants.

\section{BACKGROUND}

\section{Science Cafés as Sites for Dialogue}

The value of engaging public audiences and experts in two-way (dialogic) discussions about science topics has been well documented (Boyette \& Ramsey, 2019; Mejlgaard, 2009; Davies et al., 2009; Kerr 
et al., 2007; Lehr et al., 2007; Zorn et al., 2012). Success may vary depending on the format in which dialogue takes place between these two groups, but generally speaking, participation in dialogue results in positive attitudinal shifts and a potential convergence of attitudes between public audiences and experts (Zorn et al., 2012). In the same vein, audience members participating in dialogic discussions in educational settings benefit in terms of content comprehension whether they are participating directly in the dialogue, or if they are witnessing the dialogue as a passive participant (as opposed to being the recipient of information delivered in a strictly transmission model fashion) (Craig et al., 2000).

Rowe and Frewer (2005) catalogued three mechanisms for public engagement on the basis of flow of information. Of special interest is the "public participation" tier, also labeled "dialogue events," by which information flows in both directions between the public and the event representatives. Dialogue events serve as ideal scaffolding for social learning (Davies et al., 2009). Sociocultural and social constructivist theories for learning dictate that learning can be promoted in social contexts, for example in dialogue between individuals of different levels of expertise on a topic (Hodson \& Hodson, 1998). Bonk Jay and Kim, 1998 extend sociocultural theory to adult learning to suggest that "adult learning is enriched in collaborative and interactive learning communities with small-group discussion [...] candid conversation, social interaction, and reflection" (p.76).

Science Cafés are live public events intended for open conversation between scientists and public audiences about a determined science topic (Dallas, 1999). These events are meant to be relaxed, open, and entertaining forums, unconnected to informing policy. Prior knowledge of the science topic being discussed is not required to attend-the events are meant to be open to any member of the public, although some venue settings (i.e., bars) might restrict "any member of the public" to mean adults of legal drinking age. These events are typically held in non-academic settings. Science Cafés were first established in the United Kingdom as "a place where, for the price of a cup of coffee or a glass of wine, anyone can meet to discuss the latest ideas of science that are impacting society" (Dallas, 2006). At present, there are many variations on the Science Café format, but they typically include live presentations by expert panelists (without the use of visual aids), followed by a break and a discussion period wherein audience members might ask questions of the panelists or contribute their own knowledge or opinions to the discussion. Because the flow of information at Science Café events are intended to be in both directions between audience participants and panelists, discussion might equally focus around the importance of the issues being discussed as much as the content of the issues themselves, meaning that there is no singular goal of the discussion (e.g., expert teaching layperson with the singular goal of increasing layperson's understanding) (Davies et al., 2009). The dialogue format of the discussion period supports a social constructivist model by encouraging Science Café participants to move beyond the transmission model structure of the expert presentations and interact with the panel experts to not only facilitate their own understanding of a topic of discussion, but also to empower them to integrate their own knowledge, experiences, and perspectives into the exchange of information (Driver, 1997; Hodson \& Hodson, 1998; Davies et al., 2009).

This study uses data gathered from Science Cafés held by Science North, a science center in Sudbury, Ontario, Canada. Science North's model for Science Cafés holds consistent to the structure of panelist presentations to introduce the event's topic during the first half of the event, followed by a break and a moderated discussion period where audience participants are encouraged to approach a microphone to ask questions or contribute impressions, or to submit written questions via slips of paper or Twitter posts for the moderator to read as a proxy. With few exceptions, Science North did not hold their events at the science center; rather, as a goal for accessibility to a wider public audience, these events were held at local restaurant and bar venues in or near the city's downtown core. To further promote this accessibility, these events were free and unticketed, and the event venues were not closed to non-participant consumers. The audiences tend to consist primarily of members of the public who are already interested in the event's topic or who are seeking to deepen their knowledge of said topic; however, due to the usually free and public nature of Science Cafés, the event has the opportunity capture new audiences who have gathered at the venue for other reasons (McCallie et al., 2009).

As events, Science Cafés are structured with the intent that public audiences will engage in dialogue with the panelists and share their personal viewpoints, and that this discourse might be empowering as it removes barriers between public audiences and academic panelists (Powell and Lee Kleinman, 2008; Dijkstra and Gutteling, 2012).

There is a breadth of literature taking both quantitative and qualitative approaches to understanding why Science Café participants attend the events and how they feel about the events (Davies et al., 2009; Navid and Einsiedel, 2012; Dijkstra, 2017) and audience self-positioning as experts or non-experts in conversation with invited experts (Kerr et al., 2007); however, there is little research into understanding the nature of the questions that public audiences ask when they join the discussion at Science Cafés. In general, there is a gap in current literature with regards to public audiences at events that do not inform policy (Davies et al., 2009; Dijkstra, 2017). Studying the nature of questions being asked at these types of events can provide insights to audience participants' motivations and/or learning goals that led them to ask these questions. Studying the nature of questions being asked at Science Café events will be useful for science communicators to design events that support the interaction between event attendees' interests and goals and the information provided by the panelists. This understanding of the nature of questions can likewise be useful to scientists seeking to engage public audiences with information at informal dialogue events. The popularity of Science Café events worldwide has shown that audiences are interested in learning at these events and engaging with the science discussions being presented (Norton and Kohara, 2009). Understanding the nature of the questions being asked by these attendees will provide insight into the motivations behind the desire to learn at these 
events. If we put our audiences in situations that align with their motivations, their attention will be better focused on relevant information because they want to learn (Ram, 1991).

\section{Question-asking in the Context of Science Cafés}

Questions are expressions of learning goals, and they are often posed when the question-asker identifies a gap in their model or understanding of a topic or issue; asking the question is an act that seeks to acquire information that will correct that gap or update their understanding (Ram, 1991; Graesser and McMahen, 1993). In terms of questions as tools for learning science, (Chin and Osborne, 2008) further elaborate that "questions have the potential to 1) direct [students'] learning and drive knowledge construction; 2) foster discussion and debate, thereby enhancing the quality of discourse and classroom talk; 3) help them to selfevaluate and monitor their understand; and 4) increase their motivation and interest in a topic by arousing their epistemic curiosity" (p.3). From a social-cognitive perspective, Science Cafés are positioned to engender discussion and a similar array of learning goals to those identified by Chin and Osbourne, goals that are broader than simply "filling a gap." While earlier observational classroom studies have cited that students ask few questions, and seldom ask "high quality" questions that foster discussion (Dillon, 1998; Graesser and Person, 1994; Graesser and Olde, 2003; Carr, 1998), Science Café events differ from classroom settings in that the participants have self-selected to participate in the discussion event and have been encouraged by the format of the event to ask questions and participate in discourse. The structure and philosophy of Science Café events align with social constructivist approaches to learning in that audience participants act as social peers whose conversation allows them to co-construct knowledge and engage in meaning making (Vygotsky, 1978; Chin, Brown \& Bruce, 2002; Alexander, 2005). Finally, the open-forum structure of Science Café discussions allows for participants to explore avenues that are of individual interest to them. In a study of Grade 6 students, Chin and Kayalvizhi (2005) found that students preferred investigating questions that they constructed themselves rather than investigating the questions provided to them by a teacher or texts and that these students reported positive feelings of fun, excitement, or happiness toward the experience of investigating their own questions. By extending Chin and Kayalvizhi's findings to adult learners participating at Science Café events, understanding the natures of the questions that these participants choose to pose and investigate with event panelists will also help us understand what these question askers find interesting or exciting about the event topics.

Question generation processes, and what makes a "good" question has been studied in depth in classroom settings (Graesser and Person, 1994; Bransford et al., 1985; Ciardiello, 1998; Arbreton, 1998; Graesser and Olde, 2003). Working definitions of what makes a "good question" in classroom contexts often refers to the incorporation of cognitive processes such as memory, convergence, divergence, and evaluation
(Ciardiello, 1998). The rhetoric of qualifying questions as "good" or "poor" indicators of comprehension is less useful in the context of audience participants who ask questions at Science Cafés and similarly structured informal adult learning events. Instead, the aim of this study is to articulate the nature of the questions being asked in terms of learning objectives that motivate their asking and to investigate motivations that do not necessarily prioritize topic comprehension. A question that may not be a "good" question in the context of clarifying a task or factual knowledge in a classroom setting can still meet a learner's goal of updating their model of understanding in the context of a Science Café. The goal of a Science Café event is not typically structured such that participants will walk away from the event with expert knowledge on the events' topic; the learning goal(s) of Science Cafés are largely determined by individual audience participants, and shaped by audience-panelist interactions.

Ram (1991)'s goal-based model for learning raised two issues: one of content (What kinds of questions are there? How does the question-asker know which questions to ask?), and one of process (What difference do questions make? What effect do they have on the understanding process? How do they affect what one learns? How are questions managed in memory?) In addressing the nature of questions, in terms of learning goals, to discuss the issues of content, Ram built a computer model of question-asking with respect to seeking knowledge from textual information. His model, which required an in-depth development of theory of questions and question asking, was largely based on learning goals articulated by $\mathrm{Ng}$ and Bereiter (1991). Ng and Bereiter (1991) posited three levels of goal orientation in students: 1) taskcompletion goals; 2) instructional goals; and 3) knowledgebuilding goals. This study is also concerned with questions of content, but will need to create a new model that satisfies the nature of questions within the context of askers seeking information from live panelists at an informal learning event (specifically Science Cafés). Since audience participants at Science Cafés are not being directed to complete tasks and are not receiving instructions as students would in a formal classroom setting, $\mathrm{Ng}$ and Bereiter's model and similar models intended for evaluation the natures of questions or learning goals in classroom settings are not applicable in unadapted forms to Science Café contexts. This study proposes a new model, based on the nature of questions asked by Science Café participants, that can be used to represent the learning goals of audiences who attend informal panel discussions that do not inform policy.

As environments for learning, Science Cafés prime audiences to ask questions in ways that differ from formal classroom settings. Participants attending Science Café events do so with the shared expectation that they will have access to the panelists as knowledge sources, and that the event is intended to be a platform for discussion (and introductions to the event reinforce these expectations for participants). Sociocultural theory (Vygotsky, 1978) recommends examining the social interactions and social contexts with which classroom learning occurs. In terms of adult learning in informal contexts, we can look toward the co-construction of knowledge among peer groups, and in the case of Science Cafés, as social peers who are attending the events together, or as a larger audience peer 
group. Similarly, a social constructivist approach implies that motivation and interest in learning (including cognitive and affective engagement) is tied to the context of the social learning environment. Audiences attending Science Café events are doing so to learn in an informal social environment among peers and to access perspectives that they would not be able to access in a non-social (e.g., individual) context. Unlike a transmission-type presentation, social learning environments that encourage question-asking and dialogue can introduce alternative perspectives and new knowledge to all participants, including the expert panelists (Nussbaum, 2003). Earlier studies have provided evidence that students, when engaged in discussion, tend to incorporate one another's arguments and use them themselves (Anderson et al., 2001; Kim et al., 2007).

The nature of questions asked by public audiences are equally as informative as the answers provided by the experts being questioned in that the questions reveal the intent (informationseeking, communication of realities, preoccupations, or desires, or other) of the individual posing it (Derr, 1984; Uwajeh, 1996). By identifying emergent patterns in the natures of questions being asked by Science Café participants we will be able to better understand how public audiences question expert panels in this type of public forum and trends in question-asking behaviors. This understanding might allow us to extrapolate to audiences who do not access Science Café events and suggest approaches for public communication around challenging or controversial science topics-topics typically "up for debate" at Science Café events.

For example, in their study to both understand science café participants' views of synthetic biotechnologies and evaluate the Science Café as a forum for science communication on this specific topic, Navid and Einsiedel (2012) analyzed 28 questions from four of the five Science Cafés held in a synthetic biotechnology series and identified three themes that featured strongly at almost all of their events. These question themes were specific to the topic of synthetic biology:

1) What is synthetic biology? Is it really just genetic engineering?

2) How long will synthetic biology really take? Is it held up by research or by technology?

3) How transferable is synthetic biology technology especially for developing countries? (p.7)

Other questions raised involved concerns about environmental safety, especially in the event of an unintentional release, while others expressed worries about human safety and biosecurity. Dijkstra (2017) reviewed Science Café audience questions as evidence of audience interest and captured questions on the topic of nanotechnology: audience members asked "[...] questions about society-related topics, such as risks and benefits, ethical issues, possible fear for a new technology but, at the same time, they asked questions for clarification of the various issues that were brought up by the speakers" (p.7). Neither study provided much discussion about these audience questions nor the thematic patterns that emerge. As well, these example studies focus on audience participation in the framework of select topics (synthetic biotechnology and nanotechnology, respectively) because the goals of these types of studies tend toward identifying trends and measures in audience attitudes towards those topics of interest, given that popular topics for Science Cafés are selected on the basis that they might be controversial or in debate stages in terms of public understanding or reporting.

There is a gap in comparing audience questioning behavior across a range of topics. Is there a trend in dialogue behaviors that appears in the Science Café context that isn't necessarily bound by topic? Generally, the types of questions and dialogic contributions being put forward by public audiences at Science Cafés are underexplored. Unlike Navid and Einsiedel's, and Dijkstra's studies, which each focus on Science Café events for one topic, this study is analyzing the nature of questions asked at Science Cafés for a range of topics. As such, this study seeks to explore the nature of questions and the patterns of question-asking behaviors that are common to audience participants across Science Café topics, as well as changes in these patterns that might be associated with topic type.

\section{Existing Frameworks for Understanding the Natures and Types of Questions}

Previous frameworks for understanding question-asking have focused upon classifying students' questions in classroom settings. Famously, Bloom's Taxonomy (Bloom et al., 1956) designed a hierarchical framework as a teaching tool to classify questioning behaviors according to the complexity of the learning goals, with the recall of facts and basic concepts falling under the tier of lowest complexity, and analyzing, synthesizing and evaluating concepts residing as the layers of highest complexity. Anderson and Krathwohl (2001) rearranged and expanded upon Bloom's work to include an updated form of Bloom's "synthesis" classification, "Creating" or generating and investigating new ideas, as the most complex cognitive behavior of the framework. One limitation of these frameworks for understanding the goals of the question-askers is that they assign value to questions in terms of the cognitive complexity of their asking, rather than pointing toward interpreting the askers' motivations.

(Pizzini and Shepardsen, 1991) also developed a framework for classifying students' questions in terms of cognitive levels, but suggested instead three types of questions: input-level questions, which require students to recall information or to process sensory information; processing-level questions, by which students draw relationships among data; and output-level questions, which encompasses higher-complexity questions as represented by the top tiers of Bloom and Anderson-Krathwohl's taxonomies. With only three categories, this framework is perhaps even more restrictive than Bloom's taxonomy in terms of describing the various shapes questions may take. Taking a similar perspective, Watts, Gould and Alsop (1997) described student questions as falling into one of three categories: consolidation questions, by which students confirm their understanding or explanation for a concept, exploration questions, by which students seek to expand that understanding, and elaboration questions, by which students examine multiple claims or perspectives, test and resolve 
conflicts, and reconcile their understandings of the concept. In their review of this framework, Chin and Osborne (2006) note that because these categories reflect stages in a student's understanding of the topic, using this framework as a tool requires knowledge of when the question was asked during the process of conceptual development for the data to be meaningful.

Scardamalia and Bereiter (1992)'s research on informationseeking behaviors focused on questions as either knowledgebased (i.e., basic questions to gather information to form foundational knowledge on a topic) or "wonderment" questions, which seek to explain or resolve knowledge discrepancies, and posited that wonderment questions held greater potential to advance knowledge than orienting knowledge-based questions (Pedrosa de Jesus, Teixeira-Dias and Watts, 2003) built a framework from questions generated by undergraduate chemistry students to evaluate the students' willingness to engage in classroom interactions. They proposed a bi-polar construct that would compensate for previous models that value "high quality" questions without allowing for additional data introduced with factors such as question context, intention, and goals. The bi-polar scale that they developed classified student questions along a continuum with "confirmation questions," questions that seek to clarify, differentiate, or define, on one pole, and "transformation questions," questions that seek to restructure understanding, through hypothesis, deduction, argumentation, examination, challenge, or reasoning, on the opposite pole. By reframing question-asking behaviors in a nonhierarchical structure, Pedrosa de Jesus, Teixeira-Dias, and Watts (2003) acknowledged that more complex questions are not necessarily higher value questions since both types of questions can serve to meet the question-asker's needs.

Chin and Kayalvizhi (2002) designed a framework that classified questions as either investigable, such as questions that focus upon comparison, describing relationships, making predictions, problem-solving, or pattern-seeking, and noninvestigable questions, which referred to basic information questions where answers could be found handily without deep exploration, complex information questions where solving would involve deep theoretical exploration, or philosophical questions that could not be solved by concrete or evidence-based means.

All of the models previously described were designed to classify student questions in formal classroom settings. One model that was developed to investigate the nature of children's questions relating to informal learning was proposed by Baram-Tsabari and Yarden (2005). Baram-Tsabari and Yarden collected children's science and technology questions submitted to a series of television programs. They categorized the questions according to the topic of interest (i.e., biology, chemistry, physics, nature-of-science, etc.) to assess which streams of science were of greater interest to the students. They also assessed the children's motivations for asking the questions as "applicative," as in questions where the resultant knowledge could be applied to solve a problem, "nonapplicative," "factual," or "explanatory," and found that the bulk of questions submitted were non-applicative, with questions trending towards greater application with older question-askers.
While many models exist for describing the natures of questions generated by students and children, especially in formal learning settings, there is a gap in terms of models to describe adult questioning behaviors. This gap is even greater with respect to adult question-asking behaviors within informal learning environments. Some of the models described above may be able to provide some insight to the natures of questions asked by adult audiences at Science Café events; however, they are not designed for informal contexts, nor do they necessarily capture adult or non-student learning goals for asking questions. A question-asking framework based upon data from Science Café data does not exist. A similar approach to developing a novel framework to evaluate learning behaviors in specific informal learning settings has been shown to help us better understand the learning that is happening than the application of formal pedagogical frameworks, as in the case of informal learning through engagement with science center exhibits (Barriault and Pearson, 2010; Barriault and Rennie, 2019). Finally, all of these models work in one direction only, and do not address dialogic modes of question-asking and discussion. None of these existing models seek to identify learning goals for those who participate in information-sharing discussion without asking a question. Knowledge and opinion-sharing are an important element of the Science Café structure, whereby every audience participant has just as much opportunity to exchange their own knowledge as part of the conversation as the expert panelists do, and in doing so are a valuable part of the social constructivist aspect of these events. This study seeks to address this gap in understanding the nature of questions asked in informal learning environments such as Science Cafés as they are designed to encourage discourse and questioning behaviors, and to create a framework that is more appropriate to address informal questioning sessions. Therefore, this study will answer the question: "What is the nature of the questions asked in Science North's Science Café events?"

\section{METHODOLOGIES}

\section{Participants}

The participants in this study were attendees to Science Café events hosted by Science North in Sudbury, Ontario between November 2010 and April 2019. The participants are specifically those attendees who participated in the panel discussion period of the events and whose participation was captured by the audio recordings of the events. No additional demographics or identifying information was captured for the attendees who specifically participated in the discussion, and the audio recordings do not provide sufficient information to make inferences about demographics.

From November 2010 through April 2019, Science North hosted 55 Science Café events within public venues in the city of Sudbury. In total, audience discussion sessions were transcribed and analyzed for 41 of the 55 Science Café events. Two events from the series were excluded from the study because their format followed the PlayDecide game model, rather than a typical Science Café model, and as such no expert panel was 
invited to speak and engage with the audiences in an informal question-and-answer period. An additional 12 events were excluded because the recording files were missing and could not be provided for the study.

A total of 510 questions were transcribed from approximately 400 audience participants. The number of audience participants is approximate because, unless the participants clearly identified themselves as asking additional or follow-up questions, each question was counted as asked by a new audience participant. The number of questions within each Science Café event recording ranged from 1 to 34 questions per recording, with a median of 12 audience questions asked. Three Science Cafés included in this study had fewer than five questions available for analysis. In all cases, these low values were due to audio recording failures.

Seven questions were excluded from the transcription and so were excluded from analysis because the quality of the recording was too poor to transcribe, six because the participant was not using the microphone to speak, one because the recording cut off the question.

The Science Café recordings are being used with permission from Science North. The event recordings were collected from 2010 to 2019 by Science North, and all event recordings were released to the public on the Science North website or in podcast form. The audience were made aware that their voices would be recorded at the event and were given the option to submit their questions either electronically on Twitter or directly to the event moderator on slips of paper if they did not consent to having their voices recorded. As such, no further permission was requested for using these audio recordings for research purposes.

\section{Designing the Framework}

In order to develop a framework for understanding the nature of the questions being asked by Science Café event participants, the primary strategy for qualitative data analysis (QDA) of these data was a grounded theory approach. This approach required multiple passes of the Science Café transcripts to iterate upon the framework and reapply it to the data until theoretical saturation was met.

First pass: all transcripts were read and notes were taken for potential question-type categories. Early proposed question types based on impressions from transcripts included Factual Questions (titled Clarification Questions), Affective Questions (Bias and Opinion-Seeking Questions), Hypothetical Questions (What if Questions), and Asking for Advice. It was also noted that there existed participant engagements within the transcripts that did not pose questions and that these engagements should receive non-question codes.

Based on this pass, two parent codes were created with respect to question-asking behaviors: Information-Seeking Questions and Non-Information-Seeking Questions. The question-type categories identified during the first pass (described above) were included in the framework as subcategories of Information-Seeking Questions.

Second pass: The framework developed during the first pass was applied to all transcripts. All question-asking behaviors were coded as either Information-Seeking or Non-
Information-Seeking Behaviors, and Information-Seeking Behaviors were categorized as either Factual Questions, Affective Questions, Hypothetical Questions, or Rhetorical Questions.

During this analysis, four new Information-Seeking question types were identified: Relevance Questions (the previous Asking for Advice question type would be housed here), Rhetorical Questions, and Follow-Up Questions. These question-type categories were created to code questions that did not fit into the existing first pass framework.

Four categories for Non-Information-Seeking question types were also identified: Sharing Knowledge or Expertise Without Follow-Up Question, Storytelling or Anecdote Sharing, Criticism of Panelists' statements, and Sharing Personal Opinion on Topic to add a second layer of description for types of Non-Information-Seeking Questions found during analysis.

In order to clarify the criteria for different InformationSeeking question types and to differentiate between these question types while coding, question subtypes were identified based on observations taken during the coding process.

Affective Question subtypes:

- Questions about panelists' personal opinions or practices;

- Understanding panelists' personal goals and desired outcomes; and

- Questions about beliefs versus facts

Factual Question subtypes:

- Wh-questions (e.g., Who, What, Where, When, Why);

- Asking for definitions, fact-seeking questions, explaining a concept; and

- Causal questions (e.g., How...?)

Hypothetical Question subtypes:

- Hypothetical (e.g., What if..?) questions; and

- Future-looking questions/predictions

Relevance Question subtypes:

- Relating topic to self (e.g., Is this about personal goals or objectives that I share?);

- Asking panelists to relate topic to asker (e.g., Why does this matter to me? How does this relate to my personal goals?); and

- Asking for advice

Rhetorical Question subtypes:

- Hostile question content/challenges to panelists (e.g., Who cares? What difference does it make?); and

- Seeking Confirmation (e.g., Isn't this..?, Don't you think..?, ...right?)

Follow-Up Question subtypes: 
- Agreement;

- Persistence (disagreement or repetition of original question);

- Providing own explanation; and

- New, unrelated question

Third pass: When this new framework was applied to the transcripts and data was re-coded, the question subtypes were refined to their final state with a few exceptions:

- A new Information-Seeking question type, SolutionOriented Questions was added to encompass a pattern of askers' questions that either suggested solutions for the panelists to evaluate or requested potential solution ideas from the panel.

- The Follow-Up Question question type was removed from Information-Seeking Questions parent code to exist as an additional coding category that may be double-coded with either Information-Seeking Questions or NonInformation-Seeking Questions, where applicable. This choice was made because discrete follow-up questions may display either Information-Seeking or NonInformation-Seeking Questions and, while relevant behavioral information in terms of describing how a question-asker is engaging with others at a Science Café event (e.g., engaging in dialogic behaviors), the question category did not point to information about the asker's learning goals or to the nature of the question being asked.

- A new question subtype, Humorous Questions, was added to the Rhetorical Questions question type, to address instances where askers used humor to ask questions that otherwise did not fit with other coding categories.

- A new question subtype, Philosophical Questions, was added to the Affective Questions type, to capture questions of a philosophical nature (and as such based heavily within personal values and beliefs) that did not otherwise fit into an existing question subtype.

- Types of Non-Information-Seeking Questions were refined to Opinion or Knowledge Sharing (combining opinion-, knowledge/expertise-sharing elements into one category), Experience Sharing (which captures lived experiences and personal anecdotes), Criticism of panelists' statements, Answering Audience Questions. As well, a new type of Non-Information-Seeking Question, Promotion of event or personal cause was added to code instances where askers used their time at the microphone to promote an event or cause to the audience in the room rather than to engage the panel or audience with a question or discussion on the Science Café topic.

- Previously, only audience questions directed to the panel were being included in the study. At this juncture, the decision was made to include audience questions directed toward non-panelists or other audience members. This decision was based on the format of the Science Café, which, by its nature, encourages discussion or conversation, rather than a didactic or transmission model of information sharing. In this respect, there is value to questions posed to non-panelists within the room, just as previous passes of the data coded for the behavior of audience members answering other askers' questions. This code type exists outside of the Information-Seeking/Non-Information-Seeking parent code dichotomy, as in the case of the Follow-Up questions code, as this attribute can exist within both parent code categories. The attribute of who the asker is addressing with their question does not change the learning goal of their question.

Fourth pass: During previous passes, the question subtypes had been used as coding guidelines, or criteria, for coding questions to Information-Seeking and NonInformation-Seeking question categories. In this pass, all subtypes in the framework were included in the transcript recoding process. Therefore, every coded question would be assigned three layers of the framework (or two, in the case of Non-Information-Seeking Questions).

Theoretical saturation was reached upon reviewing and recoding all questions to a question subtype at this stage. The only major change to the framework, other than refining type and subtype titles, was to dissolve the Personal Relevance Question subtype Asking panelists to relate the Science Café topic to the asker personally, as there was only one question coded to this category and that question met the criteria to be recoded to the Personal Relevance Question subtype Relating Science Café topic to self. The distinction between the two categories was not strong enough to maintain them separately. Overall, Author 1 generated the framework and coded the transcripts for all Science Café questions; Author 2 verified the fit of the framework by applying it to a sample of 65 randomly selected questions from the transcripts.

\section{Guiding Principles}

In building the framework, every effort was made to avoid value judgments on the learning goals of the behavior categories and their subtypes. The goal of this taxonomy is not to qualify some behaviors as superior or inherently more desirable; rather, it is intended as a tool to understand the motivations or learning goals of event participants who engage in panel discussions at Science Café events and the natures of the information that they do (or do not) seek.

Classifications within the framework are not mutually exclusive; especially if participants are being coded from an audio or audiovisual source (rather than strictly text-based), participant questions can be coded to more than one category within a question-asking behavior.

All language, but especially spoken language, is rich in meaning, including intention, tone, and semantic meaning. Early research in question-asking behaviors has largely focused on text-based questions, which does not encompass the additional information that can be gathered by studying 
TABLE 1 | Comparison of question types at Science Café events featuring Challenging Topics $(n=24)$.

\begin{tabular}{|c|c|c|c|c|c|c|c|}
\hline Question type & $\begin{array}{l}\text { Number of questions } \\
\text { asked (challenging } \\
\text { science cafés) }\end{array}$ & $\begin{array}{l}\text { Percent of questions } \\
\text { asked (challenging } \\
\text { science cafés) }\end{array}$ & Mean & $\begin{array}{c}\text { Number of } \\
\text { questions asked } \\
\text { (all science cafés) }\end{array}$ & $\begin{array}{c}\text { Percent of } \\
\text { questions asked } \\
\text { (all science cafés) }\end{array}$ & Mean & $p$-value \\
\hline IS - Affective Questions & 84 & 26.33 & 3.500 & 120 & 19.93 & 2.927 & 0.183 \\
\hline IS - Factual Questions & 115 & 36.05 & 4.792 & 256 & 42.52 & 6.244 & $0.020^{*}$ \\
\hline IS - Hypothetical Questions & 58 & 18.18 & 2.417 & 87 & 14.45 & 2.122 & 0.495 \\
\hline IS - Personal Relevance Questions & 12 & 3.76 & 0.500 & 27 & 4.48 & 0.046 & $0.005^{\star}$ \\
\hline IS - Rhetorical Questions & 27 & 8.46 & 1.125 & 39 & 6.48 & 0.951 & 0.556 \\
\hline IS - Solution Oriented Questions & 35 & 10.97 & 1.458 & 74 & 12.29 & 0.180 & 0.199 \\
\hline NIS - Answering Audience Question & 3 & 0.94 & 0.125 & 14 & 2.33 & 0.341 & $0.027^{*}$ \\
\hline NIS - Criticism & 3 & 0.94 & 0.125 & 3 & 0.50 & 0.073 & 0.577 \\
\hline NIS - Experience Sharing & 7 & 2.19 & 0.292 & 20 & 3.32 & 0.488 & 0.094 \\
\hline NIS - Opinion or Knowledge Sharing & 62 & 19.44 & 2.58 & 121 & 20.10 & 2.951 & 0.560 \\
\hline NIS - Promotion & 2 & 0.63 & 0.083 & 5 & 0.83 & 0.122 & 0.509 \\
\hline
\end{tabular}

questions as they are posed in naturalistic settings; however, Carlsen (1991)'s work approaches questions from a sociolinguistic perspective and suggests that we approach three features of questions: context, which includes the speakers (in the case of this study, the audience participant, the panelists, and their relationships to each other), and where the question fits into the larger discourse between all parties; content, which refers to what is being talked about and associated knowledge; and the responses and reactions of all parties engaged in the discourse adjacent to the question-asking. As well, question askers are not necessarily conscious of their learning goals when they formulate a question and may in fact have more than one goal in mind. Taking these aspects of language and learning into account lends the data in this study to double-coding under more than one Question Type within the framework (such that data often adds up to more than $100 \%$ when taken together). As well, to reflect the nuances of language, the Question Types in this framework are not mutually exclusive types: a question may have elements of an Affective subtype while also being a Hypothetical question; a Personal Relevance-type question may also seek Factual subtype information. There are limitations within this model, however; Information-Seeking Questions and NonInformation-Seeking Questions are mutually exclusive. For example, if an asker engages by sharing a personal anecdote and then follows that anecdote with a question or a request for comment, then that anecdote is coded as part of the Information-Seeking Question, since it is a preamble to the question, providing context to the person(s) to whom the question is directed. Only if that anecdote were not followed by a question would it be coded as a Non-Information-Seeking Question.

\section{Applying the Framework}

To evaluate the framework as a tool for understanding the natures of audience participants' questions, the framework was applied to three samples of the Science Café data (samples were groupings of Science Cafés by topic type) and the resultant question-type data for those samples were compared to the data for all Science Cafés. The three sample groupings were Challenging Topics (e.g., topics that may be unfamiliar or less accessible to the public, such as gene editing or particle physics), Health Topics (i.e., events focused on human health conditions, such as hepatitis, diabetes, or fatigue), and Local Interest topics (e.g., topics of specific interest to local attendees; in the case of Sudburians, such topics include mining and environmental restoration). The differences between question-asking behavior data from the sample groupings in comparison to the data from all Science Cafés was evaluated using two-tailed one-sample t-tests. The null hypothesis states that there is no difference between the sample grouping means for each type of question-asking behavior when compared to the overall Science Café means $(p>0.05)$. Results for which the null hypothesis is rejected $(p<0.05)$ are indicated by an asterisk $\left.{ }^{*}\right)$ in Tables 1, 2.

\section{RESULTS}

\section{Explanation of the Framework}

Using a grounded theory approach to the data analysis, the framework was developed to classify participant engagements according to their learning goals (See Figure $\mathbf{1}$ for the full framework). This process yielded two main categories of question-asking behaviors: Information-Seeking Questions, by which Science Café attendees participate in the discussion period of the event with the goal of receiving information; and Non-Information-Seeking Questions, by which Science Café attendees participate in the discussion period of the event with goals that do not involve receiving information from the panelists or other Science Café participants.

Each one of the categories in the taxonomy contains, in order: 1) a definition of the question category and its overarching learning goal, including considerations for classification; 2) a description of the learning objectives(s) for each of the category's 
TABLE 2 | Comparison of question types at Science Café events featuring Health Topics $(n=11)$.

\begin{tabular}{|c|c|c|c|c|c|c|c|}
\hline Question type & $\begin{array}{l}\text { Number of questions } \\
\text { asked (health } \\
\text { science } \\
\text { cafés) }\end{array}$ & $\begin{array}{l}\text { Percent of questions } \\
\text { asked (health } \\
\text { science } \\
\text { cafés) }\end{array}$ & Mean & $\begin{array}{c}\text { Number of } \\
\text { questions } \\
\text { asked (all science } \\
\text { cafés) }\end{array}$ & $\begin{array}{c}\text { Percent of } \\
\text { questions } \\
\text { asked (all science } \\
\text { cafés) }\end{array}$ & Mean & $p$-value \\
\hline IS - Affective Questions & 26 & 13.68 & 2.364 & 120 & 19.93 & 2.927 & 0.325 \\
\hline IS - Factual Questions & 105 & 55.26 & 9.545 & 256 & 42.52 & 6.244 & 0.091 \\
\hline IS - Hypothetical Questions & 18 & 9.00 & 1.636 & 87 & 14.45 & 2.122 & 0.419 \\
\hline IS - Personal Relevance Questions & 10 & 5.26 & 0.909 & 27 & 4.49 & 0.046 & $0.013^{*}$ \\
\hline IS - Rhetorical Questions & 6 & 3.16 & 0.545 & 39 & 6.48 & 0.951 & 0.132 \\
\hline IS - Solution Oriented Questions & 20 & 10.53 & 1.818 & 74 & 12.29 & 0.180 & 0.965 \\
\hline NIS - Answering Audience Question & 7 & 3.68 & 0.636 & 14 & 2.33 & 0.341 & 0.315 \\
\hline NIS - Criticism & 0 & 0 & 0 & 3 & 0.50 & 0.073 & -- \\
\hline NIS - Experience Sharing & 6 & 3.16 & 0.545 & 20 & 3.32 & 0.488 & 0.878 \\
\hline NIS - Opinion or Knowledge Sharing & 36 & 19 & 3.273 & 121 & 20.10 & 2.951 & 0.738 \\
\hline NIS - Promotion & 2 & 1.05 & 0.182 & 5 & 0.83 & 0.122 & 0.634 \\
\hline
\end{tabular}

question subtypes; and 3) illustrative examples of questions that fit each question subtype.

\section{Information-seeking Questions}

Information-seeking questions are tools that allow Science Café participants to request information or solicit responses from the person(s) receiving the question. The following subcategories separate information-seeking questions by the learning goals of the asker, or the type of information being sought (Table 3 ).

\section{Non-information-Seeking Questions}

Audience participants engage in Non-information-Seeking Questions when their role in the dialogue is not as a questionasker or information-seeker, but rather as information contributors. The information that audience participants contribute to discourse may be factual or affective, and it may be directed toward the panelists or towards other audience members. The most important criterion for characterizing Non-Information-Seeking Questions is the lack of an actual question, whether embedded within statement or following it up. The presence of a question automatically transforms Non-Information-Seeking elements into part of (or perhaps context for) an overall information-seeking behavior. The types of Non-Information-Seeking Questions coded are described below (Table 4).

\section{Additional Question Codes}

These codes can be used to further characterize behaviors across multiple types and/or subtypes. While they do not indicate the nature of questions in terms of learning goals, they serve to reveal relevant additional information about audience participant behaviors in the context of their engagement during Science Café discussions.

\section{QUESTIONS DIRECTED TOWARD NON-PANELISTS}

This information-seeking question type is not included in the main taxonomy because the asker is not addressing the event panel; however, the behavior is interesting in that it is used to either leverage information from the audience to support the asker's statement, or it demonstrates dialogic engagement between audience members. If rich intra-audience discussion is a goal for a science café event, the presence of questions

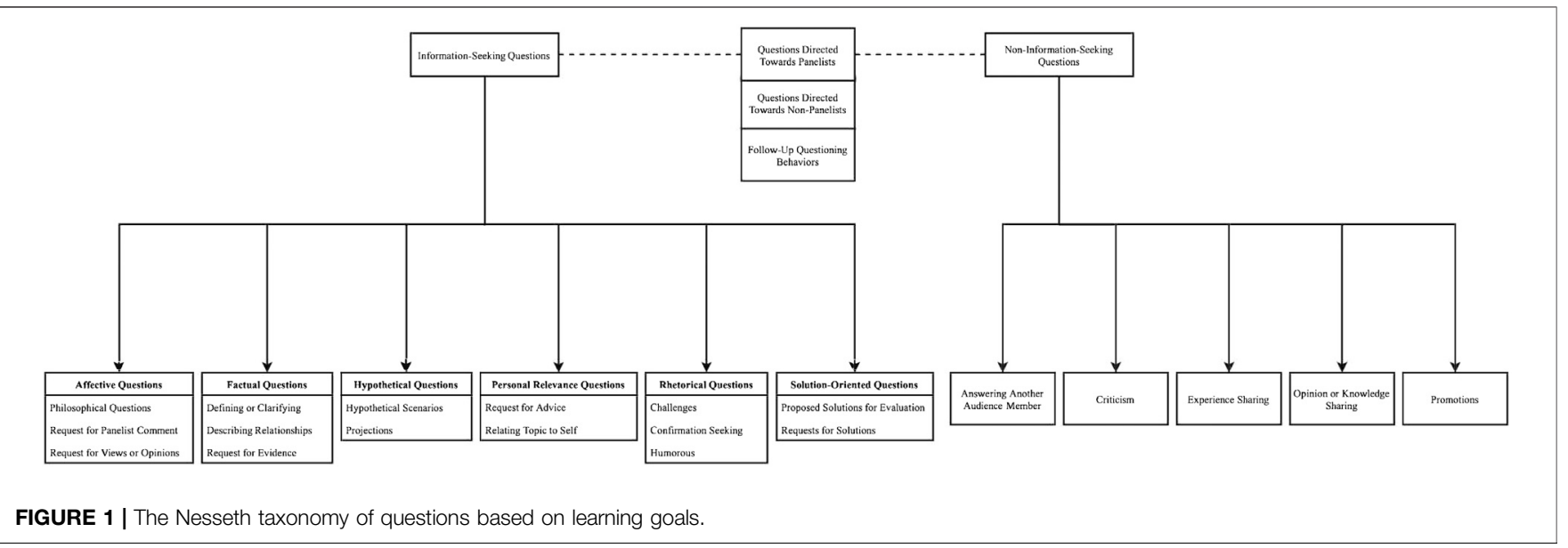


TABLE 3 | Framework layers of Information-seeking question types, subtypes, and examples.

\section{Question type}

\section{Affective Questions}

Learning Goal: Affective questions are asked to learn the panelists' personal views, opinions, or interpretations regarding information, rather than strictly factual responses. These questions will tend to be framed in a way that centers the request on the person(s) receiving the question, e.g., "Do you think?", "How do you feel..?"

\section{Factual Questions}

Learning Goal: Factual questions seek to uncover factand/or evidence-based information, including definitions, explanations, and clarifications of concepts, elucidations of relationships (e.g., causal relationships), and descriptions of real events or panelist experiences

\section{Hypothetical Questions}

Learning Goal: The goal of asking hypothetica questions is to gain panelists' views, based on extrapolating from current facts or personal speculation, regarding the future or regarding hypothetical scenarios

\section{Question subtype}

(i) Request for panelists' views or opinions The goal of the asker's question is to understand the question topic through the lens of the panelists' personal views, opinions, or interpretations of information, rather than simply receiving factual information about the topic

\section{(ii) Broad philosophical questions}

Philosophical questions are asked to request that the panelist(s) provide their reflections on broader, fundamental ideas based on the panelists' personal views, values, and beliefs. These questions typically are theoretical in nature and, as such, cannot be answered with factual information, only conjecture

\section{(iii) Requests for comment}

Requests for comment are framed as a way of seeking affirmation from the panelist(s) via panelists' opinions agreeing with theirs. Structurally, they typically follow the asker sharing their opinion or thoughts with the panel

\section{(i) Definition or Clarification}

The aim of definition or clarification questions is to receive explanations of concepts or clarifications of ideas. So-called "Wh- questions" (questions beginning with Who, What, Where, When, or Why) are encompassed within this subtype. This subtype also includes closed fact-seeking questions that can be answered with a yes or no

\section{(ii) Description of Relationships}

This subtype seeks factual information regarding relationships, such as causal relationships, correlations, or comparisons and contrast relationships

\section{(iii) Requests for Panelists' Lived Experience}

Rather than seeking views or opinions, this subtype seeks to learn panelists' concrete, lived experience as evidence to support an idea or argument

\section{(i) Hypothetical Scenarios}

Hypothetical scenarios ask the panelists to speculate on given hypothetical scenarios and usually involve the panelists' personal views, opinions, beliefs, and/or personal interpretations of the asker's hypothetica scenario

\section{(ii) Projections}

Requests for projections seek specifically for the panelists to evaluate current data and formulate projections or predictions based on this data

\section{Examples}

"How do you feel - so you all expressed your views about how the environment and genetics are so complicated. How do you feel about genetically modified organisms? Genetic engineering in general?"

"[...] do you really feel the mining companies in Sudbury, in the basin, are really prepared for embracing technology?"

"Without consciousness, do we own our body?" "We've talked a lot about the impact of both genetics and the environment and how they work together. Um, my question is: where does free will play into this?"

"And, I don't know: do you want to comment on that comment?"

"And so I was wondering what you guys think about that strategy."

"Is there research that you can speak to that kind of clears that up a little bit?"

"Who makes these detectors?"

"[...] how does behavior, like say, suckling on breasts in mice or inhaling particulate matter lead to fairly specific organic chemistry changes within the nucleus of the cell?"

"How does it compare to other countries?"

"And do you find this same problem in your scientific papers that I'm seeing in engineering papers?"

"So the question is: what types of medical emergencies have you encountered that marijuana might have been involved in?"

"[...]can we imagine two different islands and on one island we have 100 women and one man, and on another island we have 100 men, one woman. And from female-male behavior-point of view or biological evolution point of view, if somebody were to visit these two isolated islands after $2 \mathrm{yr}$, what kind of a change you will (sic) expect?"

"As well, a proper question: next week and at the opening: fantastic! You flip a switch and you discover dark matter. What next?"

"Can you give a prediction of what timeframe that might be? I know it's a bit of a crystal ball thing, but where it is right now and where it's looking to go?"

"So, in the next $20 \mathrm{yr}$, what, what do you project happening? Is it more successful research? Is it more research is being involved that can perhaps advance that, that, that you want to be advanced?"

(Continued on following page) 
TABLE 3 | (Continued) Framework layers of Information-seeking question types, subtypes, and examples.

Question type

\section{Personal Relevance Questions}

Learning Goal: The goal of the personal relevance question is to relate the topic personally to the asker. The asker seeks to make a personal, often emotional, connection to the topic to either support understanding of the topic or to deepen their appreciation for that topic's importance or relevance

\section{Rhetorical Questions}

Learning Goal: Rhetorical questions are vehicles for assertion. They allow the asker to emphasize a point or to reinforce an idea or statement, to seek confirmation of personal view, to challenge panelists or establish disagreement

\section{Question subtype}

\section{(i) Asking for Advice}

As a goal, the asker is seeking advice from the panel, either to assist themselves, or to assist others, in making a decision or taking an action

\section{(ii) Relating Topic to Self}

By relating the discussion topic to themselves and making personal connections, the asker seeks deeper understanding or reason for deeper interest in the topic

\section{(i) Challenges}

Challenges allow the asker to establish disagreement, with the goal of provoking the panelists to either revisit or deepen their argument. This subtype may also encompass "playing the devil's advocate."

\section{(ii) Confirmation-Seeking Questions}

Confirmation-seeking questions, often appearing as filler language or a non-question (e.g., "right?") seek to assert a statement while asking for the panel to confirm or agree with the statement

\section{(iii) Humorous Questions}

Humorous questions can serve a few roles. They may be used as a way for the asker to build comfort prior to entering discourse with a "real" question, or to couch a true information-seeking behavior within a joke to avoid negative affect, such as embarrassment about their own lack of knowledge; they may be used to seek social validation from the panel or other audience members; or they may be used to elicit a positive affective response from the panel

\section{(i) Proposing solutions for evaluation}

Learning Goal: The goal of solution-oriented questions is to prompt discussion towards a solution to an issue raised either directly or indirectly by a Science Café topic
This subtype involves the asker proposing an idea for a solution and soliciting the panel's opinion as to that proposed solution's feasibility, based on their expertise

\section{(ii) Requests for solutions}

This subtype occurs when an asker identifies an issue and sees a need for a solution, but does not have a solution to propose to the panel; rather, they deliver the need for a solution to the panel and ask for the panel to consider and describe possible solutions

\section{Examples}

"Who do you go to see if, like we had a young girl, she couldn't even drive her car home, we had to drive her car home. She got so stressed out and sick. And I think, who do you recommend these people to go to see?" "So, what do you guys recommend for people trying to eat more of a plant-based diet and where they can get their so-called protein and make sure they're eating a well-rounded diet?"

"And what I am, just with my two neighbours, so...the question always comes back: why should I care?"

"Like, why is it that my friends in New York and some friends in Toronto are on PREP but then, like, what's wrong with Canada with that respect?"

"You talk about these scientists having this discussion. I wonder if scientists can also be blinded by the fact that they never actually tested that clouded their decision to allow it to go that long."

"So, who is going to argue on the positive side? Even that might not be true."

"If most of us feel that way, aren't we then really talking about consciousness?"

"It sounds as though the structure at the MNR changes quite frequently, right?"

"[...] can I be the first volunteer to be your guinea pig in the environmental chamber, please?"

"So I have two questions: one is quite easy, uh, the second one's a bit longer. The first: dark matter? Is that similar to Star Trek's equivalent to anti-matter?"

"Just on the green energy thing. Um, I wondered how much, how long the lifespan of the Superstack would be and if it would be feasible to clad it in solar panels rather than tear it down for energy?"

"Just a wild idea: have people considered the use of virtual reality on animals to prepare them for life in the wild?"

"What do we do?"

"How do we build a culture that would be excited about exploring science?" directed toward non-panelists may be used as a relevant and measurable engagement behavior.

Examples:

- [in response to another audience member] "Why?"

- "[...] how many people in the audience were born 1981 or onwards?”

\section{Follow-Up Questions}

Follow-up questions were also coded as part of audience engagement analysis because they indicate depth of engagement, either in terms of an asker's interest in asking multiple questions of the panel, or in terms of an asker engaging in a dialogic, conversational pattern of engagement with the panel. Follow-up questions may be either discrete, pre-planned questions asked in succession, the same 
TABLE 4 | Framework layers of non-information-seeking question types and examples.

Question type

\section{Answering Other Audience Members}

This behavior occurs when an audience member has knowledge or an opinion related to another asker's question and chooses to share this information, either to fill a perceived gap in the panel's response to asker, or to add to the panel's response

\section{Criticism}

Criticism allows for the asker to share their displeasure, disagreement, or other negative affect with the panel and greater audience. This behavior can be differentiated by the "challenges" subtype of the Rhetorical Question categorization in that the asker seeks to make their assertion of disagreement without the expectation of response from the panel

\section{Experience Sharing}

Experience Sharing provides the asker with a vehicle for describing their lived experience to the panel and greater audience as evidence to support their argument with respect to the Science Café topic. This behavior does not precede a question or other information-seeking engagement

Opinion or Knowledge Sharing

Opinion or Knowledge Sharing provides the asker with a vehicle for asserting their personal views, beliefs or values, or to share their personal knowledge relating to Science Café topic. This behavior does not precede a question or other informationseeking engagement

Promotion

When presenting promotion statements, participants are taking advantage of the gathering at the event to use the discussion period as a platform to bring awareness to a person, organization, event, or cause, and/or are inviting other event participants to engage in a call to action

panelist returning to the microphone ask an additional question, or the asker engaging in a back-and-forth discussion with the panelists, responding to the panel's response to their questions with questions addressing the new information provided by the panel.

- "I've got another question, it's that, with regards to, um, is there anything that could, perhaps, buffer the effects of this?"

- [in response to a panelist's response to their question] "So, our policy decisions on conservation are driven by aesthetics?"

\section{Information-Seeking Questions Among Science Café Participants}

The majority of audience participant engagements at Science Café events involved information-seeking questions (76.41\%) as opposed to non-information-questions (23.59\%). In terms of information-seeking questions, askers most often sought factual information (42.52\%); in particular, askers sought definitions of terms or clarifications of concepts from the panel. The second most popular form of information-seeking question came in the form of affective questions (19.93\%), in particular, questions that specifically sought the panel's views or opinions (14.95\%) (Figure 2 and Table 5).
Examples

"Um, l'd like to address the specific question that was asked just previous to this, with regards to whether the money would be better spent on some sort of medium, um, like radio... I still feel that any type of medium wherever you actually want to advertise, wherever you can get the best bang for your buck, would be ideal."

"If I can just add a bit to that. Having both diseases makes each other worse in the long term. Hep C will complicate HIV, and HIV will complicate the Hep C in terms of treatment."

"Um, I'm going to play "devil's advocate" and say that, and at risk of shocking the entire audience, I think that you are, all of you, micturating into a very strong breeze." "I just wanted to ask, tell you I mean, what I don't like about the game - their situation is different, but with the children? I just find that all the people that are in the games all look perfect again. You know what I mean? So, that really bugs me. I like that show with Johnny Depp where he was Captain of the Caribbean? Everybody was like a monster. Like they were all different monsters. I just find that it's just too bad that that game has to have everybody looking perfectly shaped and very beautiful and it's sad that part of me in the game."

"Well, a supplementary, and I don't want to get too, sort of, detailed about it, but l'd, I'm a physician. I do talks on the physical and the, you know, health risks to do with climate change."

"I come from a rural community, a First Nation community on Manitoulin Island and I'm, it's good to hear the challenges that people face in the city, that we also face in a rural community."

"Oh I was just going to add that his bone marrow donor? He was one of those few people who is non-susceptible to HIV. That mutation that's present in Europe."

"And, uh, I think that we could learn a, for example, um, I think it all has to do with our biochemistry and, um, take a type I diabetic and feed him all you want, he's not gaining weight. And, uh, I think we need to look at, uh, these things from a very personal way, because everybody's biochemistry is different."

"So, if anyone has stories they would like to share, or anecdotal evidence that they have been able to protect their information thanks to this new law, we can show them that it's working. Feel free to connect with the coalition. We'll be happy to share your stories for you. Thank you very much for the presentation."

"So, I suggest to all of you to check it out and get involved with citizens' climate lobby. So, that was the non-political pre-debate announcement."

\section{Non-Information-Seeking Questions Among Science Café Participants}

During question and answer sessions at Science Café events, just over one-fifth $(23.59 \%)$ of audience participant engagements were Non-Information-Seeking questions. Most of these questions (20.10\% of all engagements) involved the participant sharing their personal opinion or knowledge without including a question in their remark. Participants at Science Café events were much less likely to approach the microphone for the purposes of sharing personal experience (3.32\%), answering other audience members' questions or engaging in dialogue at the microphone with another audience member $(2.33 \%)$, using the event as a platform to promote events or personal causes $(0.83 \%)$, or criticizing the panelists (0.50\%) (Figure 3 and Table 5).

\section{Other Engagement Behaviors Among Science Café Participants}

Types of dialogic behaviors that went beyond the two-step practice of 1) posing a question to the panel, and 2) receiving the answer from the panel included: 1) follow-up questioning, by which audience participants either responded to the panelists' response with a related question, repeated their own question, or 


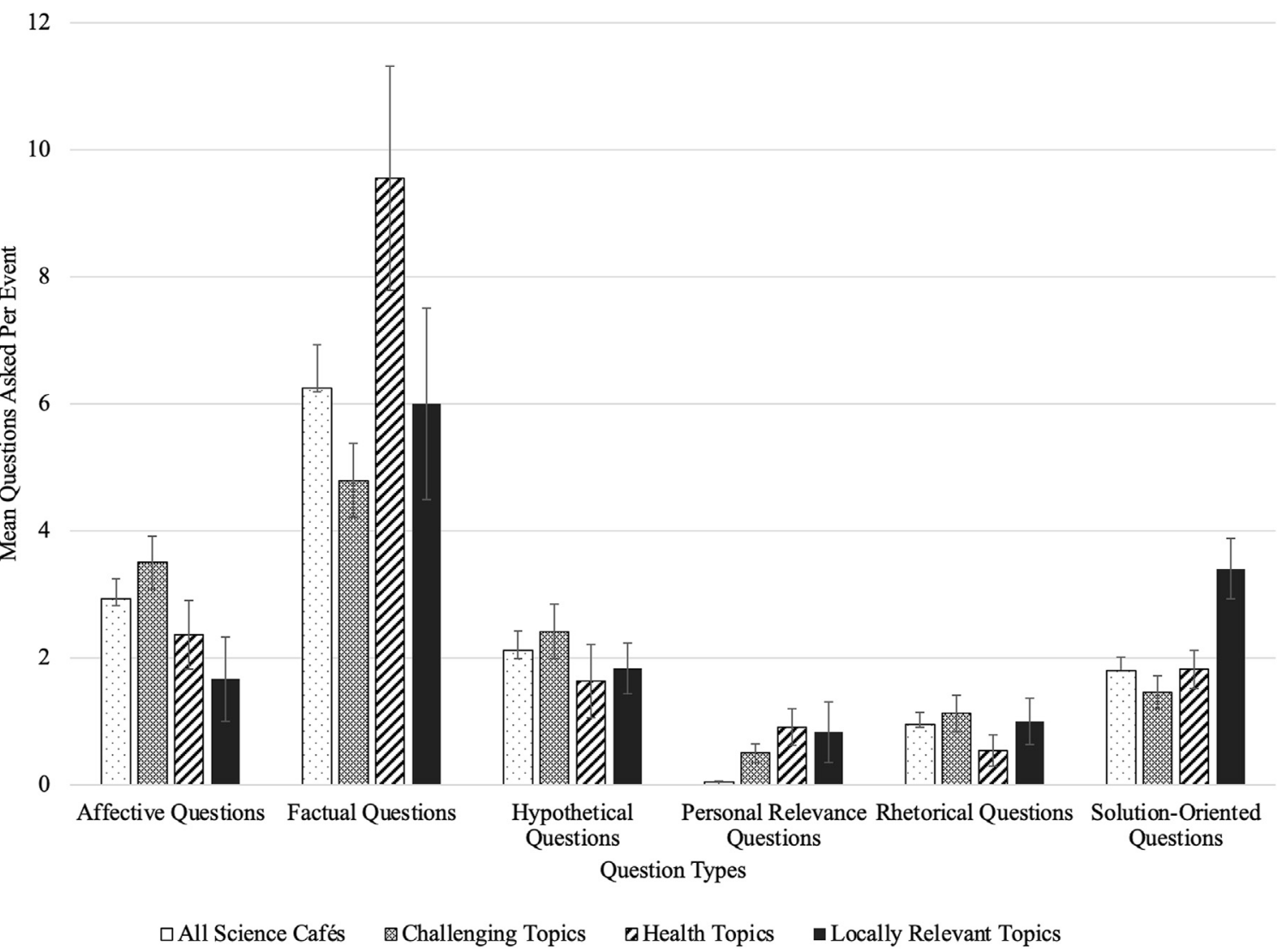

FIGURE 2 | Information-seeking question types for all Science Café events.

continued a line of questioning with a new, unrelated question, and 2) questions posed to other audience members to invite their input in the discussion. Follow-up questions made up approximately $13 \%$ of the engagements during Science Café discussions. Engaging other audience members was a less common behavior, with fewer than $1 \%$ of engagements being addressed to non-panelists. There was no significant difference in these dialogic behaviors across different Science Café topic types.

\section{Impact of Science Café Topic on Asker Behavior}

The primary application of the framework is to measure the frequencies of question types and subtypes asked by Science Café participants in order to gain insights about the natures of questions being asked at these events. To evaluate the framework as a tool capable of providing comparative data about the natures of questions being asked by audience participants when specific topic types are featured, the framework was applied to groups of Science Cafés (grouped by topic type), and the question-type data from these groupings was compared to the total data for all Science Café events. When grouped by topic, three major categories of Science Cafés emerged: 1) Challenging topics $(n=24)$, which consist of complex, challenging, and/or theoretical topics that likely do not have immediate personal relevance to the audience, or topics to which the audience may have had limited exposure, such as particle physics or genetic engineering; 2$)$ Health Topics $(n=11)$, which comprise topics that are immediately relevant to human health, such as diabetes and depression, and fatigue; and 3) LocallyRelevant Topics $(n=6)$, which consist of topics that are specifically relevant to the local interests of, or local issues affecting Science Café attendees (in this case, as predominantly residents of the City of Greater Sudbury), such as mining or local environmental remediation efforts (known colloquially in this area as "regreening").

As we can see in Table 1 above, when the Science Café features a Challenging topic (e.g., biotechnology or gene editing), we actually see a decrease in Factual question types and an increase in Personal Relevance question types. The percentage breakdowns for subtypes of Affective Questions were comparable to the overall breakdowns for those subtypes across all Science Café events. questions is that the learning goal of the asker isn't to seek definition or clarification of these topics or the issues surrounding them in evidence-based terms (terms which would have been presented to some degree during the panelists' presentations in the first half of the Science Café event); rather, they are seeking to build their knowledge and opinions on these topics or issues using by asking the expert panelists to draw connections to the topic on terms that are personally relevant to the question asker. This is an interesting 
TABLE 5 | Frequencies of all types and subtypes of question-asking behaviors.

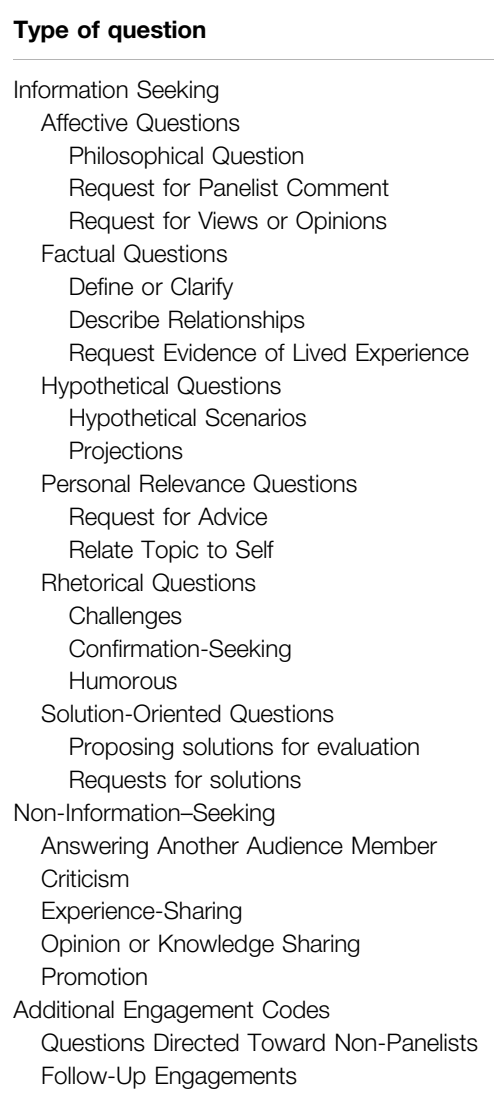

\begin{tabular}{|c|c|}
\hline Frequency & $\%$ of total questions \\
\hline 460 & 76.41 \\
\hline 120 & 19.93 \\
\hline 21 & 3.48 \\
\hline 12 & 1.99 \\
\hline 90 & 14.95 \\
\hline 256 & 42.52 \\
\hline 197 & 32.72 \\
\hline 55 & 9.14 \\
\hline 17 & 2.82 \\
\hline 87 & 14.45 \\
\hline 61 & 10.13 \\
\hline 26 & 4.32 \\
\hline 27 & 4.49 \\
\hline 11 & 1.83 \\
\hline 17 & 2.82 \\
\hline 39 & 6.48 \\
\hline 7 & 1.16 \\
\hline 28 & 4.65 \\
\hline 5 & 0.83 \\
\hline 74 & 12.29 \\
\hline 28 & 4.65 \\
\hline 50 & 8.30 \\
\hline 142 & 23.59 \\
\hline 14 & 2.32 \\
\hline 3 & 0.49 \\
\hline 19 & 3.16 \\
\hline 121 & 20.10 \\
\hline 5 & 0.83 \\
\hline-- & -- \\
\hline 5 & 0.83 \\
\hline 88 & 14.62 \\
\hline
\end{tabular}

finding that contrasts with previous research conducted by Scardamalia and Bereiter (1992), which found that students generated mainly Factual-type "basic information" questions for topics that were less familiar to them, but concentrated on "wonderment" questions (defined by Scardamalia and Bereiter (1992) as questions that reflect curiosity, puzzlement, or speculation) when they were more familiar or comfortable with the subject matter being discussed.

When the Science Café topic is focused upon human health, the results show a shift in asker behavior that also favors Personal Relevance question types (Table 2). indicating that the goals of participants at Science Cafés featuring health topics is to discuss health issues in terms that are applicable to their personal experiences. We might infer that these question askers are interested in concrete information over abstract because health issues are inherently more personal, more likely to affect them or someone that they know, than impersonal-seeming topics such as foreign aid projects or particle physics. Question-askers are seeking information that they might be able to apply in the case that they or someone close to them is affected by the health issues being discussed.

All of the Science Café events included in this study were held at locations in Sudbury, Ontario, Canada, and the majority of attendees are assumed to have been either permanent or temporary (i.e. student) inhabitants of the Greater Sudbury region. While any topic addressed during a Science Café might be filtered through a local lens, six Café topics in particular addressed issues that are highly relevant to the people of Greater Sudbury, their culture, and the City's economy (e.g., regreening or environmental restoration, mining). Topics known to be of high interest to local audiences yielded different question-asking patterns, most notably a large shift toward Solution-Oriented question types (Table 6). This shift in Information-Seeking Questions indicates a tendency towards ownership or personal affiliation with the topic and a desire to make improvements, whether by suggesting solutions to the panel for issues that they have perceived relating to the Science Café event topic, or by identifying the need for a solution and entreating the expert panel to conceptualize potential solutions. Interestingly, while audience participants did engage in sharing personal experiences and opinions as Non-Information-Seeking Questions, there is no significant increase in these behaviors when compared to all Science Café events. This is likely because these sharing behaviors were often tied to a Solution-Oriented (or other) learning goal and so were not captured separately as NonInformation-Seeking Questions.

Overall, the types of questions asked in these three groupings of Science Café types did not yield significant shifts in noninformation-seeking question asking behaviors when compared to the full set of questions asked by audience participants at all Science Café events included in this study (Figures 2, 3 and Tables 1, 2, 6). One exception was measured: audience members who participated in Science Cafés featuring a Challenging topic of 
6

5

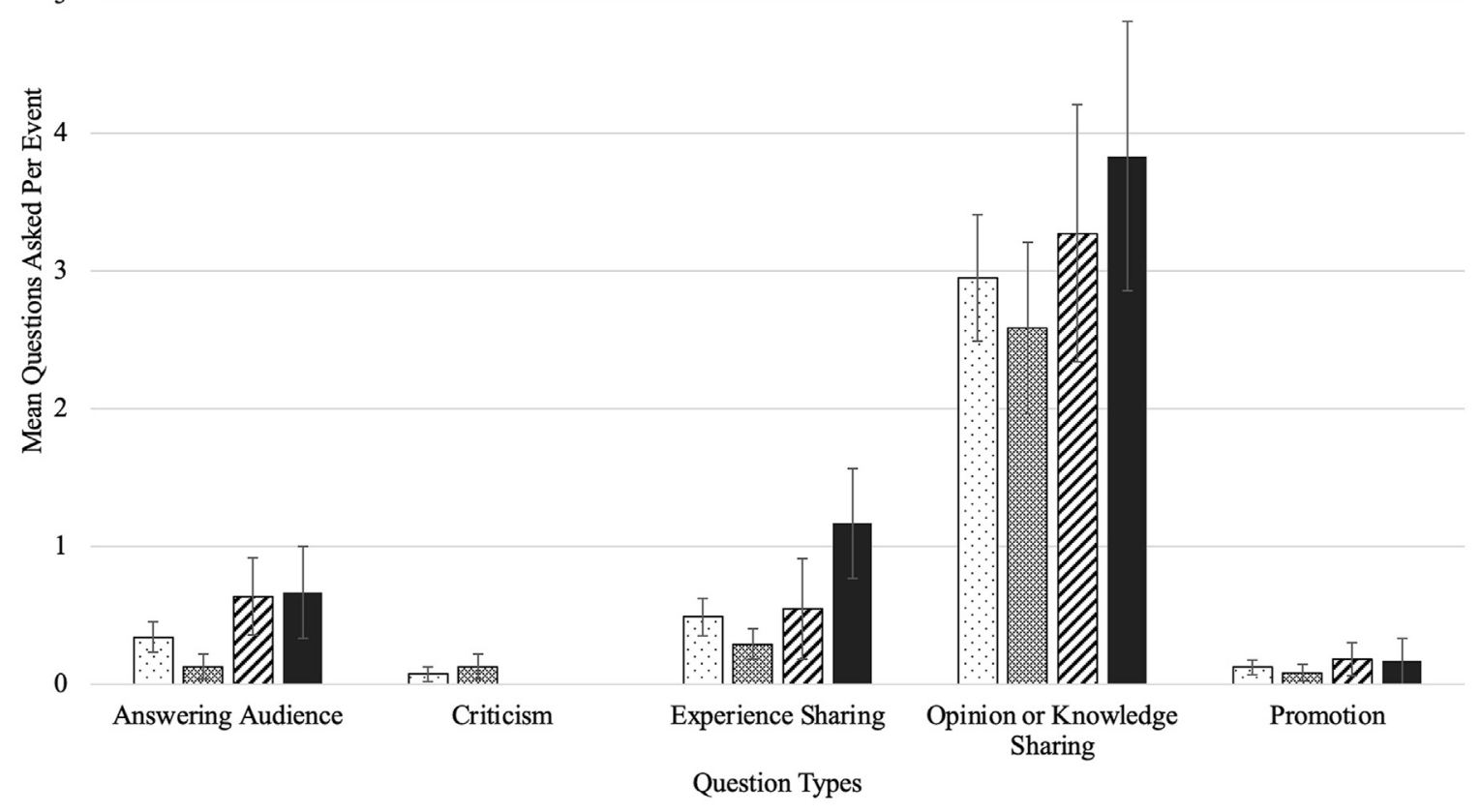

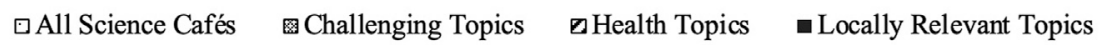

FIGURE 3 | Non-Information-seeking question types for all Science Café events.

TABLE 6 | Comparison of question types at Science Café events featuring Locally-Relevant Topics $(n=6)$.

Question type

Number of questions
asked (locally
relevant
science cafés)

IS - Affective Questions

IS - Factual Questions

IS - Hypothetical Questions

IS - Personal Relevance Questions

IS - Rhetorical Questions

IS - Solution Oriented Questions

NIS - Answering Audience Question

NIS - Criticism

NIS - Experience Sharing

NIS - Opinion or Knowledge

Sharing

NIS - Promotion

Percent of questions Mean
asked (locally
relevant
science cafés)

9.09

32.73

10.00

5.61

5.45

17.27

3.64

0

6.36

20.91

0.91

Number of
questions
asked (all science
cafés)

1.667

6.000

1.833

0.833

1.000

3.400

0.667

0

1.167

3.833

0.167

120
256
87

87

27

39

74

14

3

20

121

5

Percent of
questions
sked (all science
cafés)

\begin{tabular}{ccc}
19.93 & 2.927 & 0.117 \\
42.52 & 6.244 & 0.877 \\
14.45 & 2.122 & 0.504 \\
4.48 & 0.046 & 0.160 \\
6.48 & 0.951 & 0.898 \\
12.29 & 0.180 & $0.020^{*}$ \\
2.33 & 0.341 & 0.374 \\
0.50 & 0.073 & -- \\
3.32 & 0.488 & 0.152 \\
20.10 & 2.951 & 0.409 \\
& & \\
0.83 & 0.122 & 0.799 \\
\hline
\end{tabular}

discussion were less likely to engage in answering other audience members' questions (Figure 3 and Table 1).

\section{DISCUSSION}

The results of analyzing the transcripts of 41 Science Café discussion sessions allowed for the development and application of a coding framework of questions based on the asker's learning goals. In turn, the application of this framework allowed us to understand the nature of the questions being asked by audience participants at Science Café events.

The framework took the form of a taxonomy of question types (Figure 1), wherein emergent themes in how audience participants engaged during Science Café discussion sessions revealed an order of behaviors. Constructing the framework 
as a taxonomy reflects this order in the nature of questions and behaviors from broad descriptors (e.g., whether the behavior was information-seeking or not), and moving toward more specific descriptions of the nature of those behaviors (e.g., whether that information-seeking behavior was more specifically asking questions that seek factual information, and then whether that factual information sought was to describe relationships).

The classification schema for this taxonomy represents audience participant behaviors in terms of the intent behind their participation during Science Café discussion sessions. These intents can be described as learning objectives, and because these sessions are dialogue events, learning objectives encompass information that the audience participants wish to receive (Information-Seeking Questions) as well as information that the audience participants wish to impart (NonInformation-Seeking Questions). As revealed by the analysis of the audience participants' questions, the learning objectives are not limited to the acquisition of factual information (nor the delivery of strictly factual information); rather, when engaging with a live panel of experts, audience participants are also interested in acquiring personal and affective information that is not necessarily evidence-based. In other words, audience participants are interested not only in what they can learn about a topic or issue, but they would like to inform themselves of how others feel about those topics or issues (and to share with others how they themselves feel), with a goal of integrating others' values, feelings, or beliefs into their understanding.

\section{Toward Increasing Audience Dialogue at Science Cafés}

By breaking out the data in terms of the types of questions asked at Science Café events with specific topic types, we were able to observe shifting trends in how askers' learning goals changed made visible through the types of questions that they were asking.

While audience participants at Science Café events demonstrated similar Information-Seeking question-asking behaviors across all topic types, Challenging Science Cafés demonstrated a significant decrease in audience participants who stepped up to the microphone during panel discussions to answer another audience member's question, either by positing an opinion or sharing their own knowledge on the topic (a non-information-seeking behavior). In what is the largest grouping of Science Cafés (58.54\% of all Science Cafés), only three participants engaged in this behavior. This decreased behavior implies a lack of comfort or familiarity with the topics of discussion-when paired with a significant increase in Personal Relevance question types, the implication becomes one of question askers seeking relevance to build comfort. More easily apprehensible or personally-relevant topics, such as those found in the Locally-Relevant Science Cafés might promote easier dialogue between audience participants at Science Café events.

As public events intended as sites of science communication through dialogue. this change in question-asking among audience participants attending Science Cafés discussing more challenging, complex, or abstract topics might present barriers to discussion, relegating the events to transmission-model presentations, where experts are exclusive providers of knowledge and audience participants are receivers of knowledge. It is poignant that, although there was a marked decrease in audience members engaging in dialogue with each other, there was no parallel decrease in other non-information-seeking question-asking behaviors, such as opinion-sharing, or knowledge-sharing directed toward the panelists. Further research would be required to understand if there is a perceptual shift in how audience members view each other as discursive partners as topics of discussion become more complex.

The changes in question-asking among audience participants for different types of Science Café topics indicate that Science Café event attendees' learning goals change depending on the type of Science Cafés that they are attending. Generally speaking, understanding audience behaviors with respect to their learning goals is useful for science centers, museums, or educators hosting Science Café events because event topics can be selected to support those centers' event goals (if any exist). Likewise, science communicators and panelists (or the organizations hosting the events) can be better prepared for the nature of questions likely to be asked given a topic type, or can modify their presentations of material to meet audience learning goals (for example, introducing more opportunities for audience participants to contribute responses to other audience members Science Café events focused upon a Challenging topic).

\section{Recommendations for Future Study}

The data collected for this study was collected solely from Science Café events. Further research would be needed to confirm that the participant behaviors observed at Science Cafés translate to nonScience Café learning events, such as panel discussions that do not follow a Science Café structure, or formal presentations followed by question and answer sessions, and that the framework can, in those cases, be applied effectively. It is possible that differently-structured learning events will yield different environments that either encourage or discourage question-asking behaviors. To illustrate event-specific challenges, while there is a lack of research in the area of the nature or content of questions asked at academic conferences, Telis et al. (2019) observed that the social culture and internal factors such as biases at academic conferences affected the participation of women during discussions at panels regardless of their representation within the audience population. They also found that public intervention outside of conference spaces acknowledging under-participation in women can cause an increase in their participation at subsequent events (an effect that can be attributed to changed expectations on behalf of the audience participants). Previous studies have cited similar gender differences in terms of conference questionasking behaviors (Hinsley et al., 2017; Carter et al., 2019; Davenport et al., 2014). It stands to argue that, if contextual factors are influencing who among audience participants are engaging in question-asking behaviors, then these factors 
may also affect the natures of the questions being asked. These factors may encompass speaker delivery, demeanor, and-as indicated in this study-event topic. It is also possible that the different natures of other, non-Science Café informal learning events produce different learning motivations, and therefore different question types and subtypes not captured within a framework developed using only audience data from Science Café events.

In terms of audience context influencing question-asking behaviors, very little demographics data was collected by Science North at the Science Café events researched in this study; however, many audience participants did introduce themselves during their engagements by self-identifying as either experts or non-experts. An interesting future avenue of research would be to analyze these incidences of selfidentification to evaluate whether relationships exist between an asker's self-designation as an expert or non-expert and the nature of questions being asked. There is an opportunity here to expand upon Kerr et al.'s work (2007) on the topic of participants self-identifying as experts or non-experts at activities that employ public dialogue about science, technology and medicine.

This study sought to understand the natures of audience questions at Science Café events-understanding the audiences who attend these events allows for these events to be constructed not only in a fashion that encourages question-asking, but that creates a conversational environment that promotes the comfort of all audience members to engage in the activity of questionasking, no matter the question-asker's prior knowledge or overall comprehension of the event topic. Science Cafés as events already serve to break down some barriers to non-expert audiences by virtue of being organized informal events built to answer questions in a dialogic manner in casual settings. Rather than extrapolating from formal education learning frameworks that are built to evaluate the cognitive complexity of question-asking behaviors as a measure of learning success, this framework was grounded in the informal question-asking behaviors that Science Café audience participants already display, allowing us to "meet them where they are," and recognize and support the personal learning goals that motivate them to attend and participate

\section{REFERENCES}

Alexander, R. (2005). Towards Dialogic Teaching. York, UK: Dialogos.

Anderson, R. C., Nguyen-Jahiel, K., McNurlen, B., Archodidou, A., Kim, S.-y., Reznitskaya, A., et al. (2001). The Snowball Phenomenon: Spread of Ways of Talking and Ways of Thinking Across Groups of Children. Cogn. Instruction 19 (1), 1-46. doi:10.1207/S1532690XCI1901_1

Arbreton, A. (1998). "Student Goal Orientation and Help-Seeking Strategy Use," in Strategic Help Seeking: Implications for Learning and Teaching. Editor S. A. Karabenick (Mahwah, NJ: Lawrence Erlbaum Associates Publishers), 95-116.

Baram-Tsabari, A., and Yarden, A. (2005). Characterizing Children's Spontaneous Interests in Science and Technology. Int. J. Sci. Edu. 27 (7), 803-826. doi:10.1080/09500690500038389

Barriault, C. L., and Rennie, L. (2019). The Development of a Standardized Assessment Framework for Animal Exhibits. Visitor Stud. 22 (1), 21-42. doi:10.1080/10645578.2019.1603737 during Science Café discussions. Just as Telis et al. (2019) observed changes in participation behaviors with some public intervention geared toward improving the comfort of conference spaces for women, this study can act as a step toward structuring Science Café events and similar informal public engagement in science events in ways that not only understand their audiences as learners, but that also cultivate these events as spaces that support question-asking for all audience members.

\section{DATA AVAILABILITY STATEMENT}

Publicly available datasets were analyzed in this study. Example transcripts are included in the supplementary material. For all transcripts and access to the original audio files used in this research, please contact the corresponding author.

\section{AUTHOR CONTRIBUTIONS}

NN conceived and developed the framework and performed data analysis. AH verified the analytical methods and results. $\mathrm{NN}$ wrote the manuscript in consultation with $\mathrm{AH}$ and $\mathrm{CB}$. $\mathrm{AH}$ and $\mathrm{CB}$ supervised the project. All authors provided critical feedback and helped shape the research and manuscript.

\section{ACKNOWLEDGMENTS}

The authors would like to acknowledge Science North for providing the audio recordings of their Science Café events for analysis.

\section{SUPPLEMENTARY MATERIAL}

The Supplementary Material for this article can be found online at: https:/www.frontiersin.org/articles/10.3389/feduc.2021.674878/ full\#supplementary-material.

Barriault, C., and Pearson, D. (2010). Assessing Exhibits for Learning in Science Centers: A Practical Tool. Visitor Stud. 13 (1), 90-106. doi:10.1080/ 10645571003618824

Bloom, B. S., Engelhart, M. D., Furst, E. J., Hill, W. H., and Krathwohl, D. R. (1956). Taxonomy of Educational Objectives: The Classification of Educational Goals: Handbook I. New York, NY: Cognitive domainMcKay.

Bonk Jay, C., and Kim, K. A. (1998). "Extending Sociocultural Theory to Adult Learning," in Adult Learning and Development: Perspectives from Educational Psychology. Editors M. C. Smith and T. Pourchot (New York, NY: Routledge), 67-88.

Boyette, T., and Ramsey, J. (2019). Does the Messenger Matter? Studying the Impacts of Scientists and Engineers Interacting with Public Audiences at Science Festival Events. Jcom 18 (02), A02. doi:10.22323/2.18020202

Bransford, J. D., Arbitman-Smith, R., Stein, B. S., and Vye, N. J. (1985). "Improving, Thinking and Learning Skills," in Thinking and Learning skillsRelating Instruction to Research. Editors S. F. Chipman and R. Glaser (Hillsdale, NJ: Lawrence Erlbaum Associates), Vol. 1.

Carlsen, W. S. (1991). Questioning in Classrooms: A Sociolinguistic Perspective. Rev. Educ. Res. 61(2), 157-178. doi:10.1080/09500690500038389 
Carr, D. (1998). The Art of Asking Questions in the Teaching of Science. Sch. Sci. Rev. 79, 47-50.

Carter, A. J., Croft, A., Lukas, D., and Sandstrom, G. M. (2019). Correction: Women's Visibility in Academic Seminars: Women Ask Fewer Questions Than Men. PLoS ONE 14 (2), e0212146. doi:10.1371/journal.pone.0212146

Chin, C., Brown, D. E., and Bruce, B. C. (2002). Student-generated Questions: A Meaningful Aspect of Learning in Science. Int. J. Sci. Edu. 24 (5), 521-549. doi:10.1080/09500690110095249

Chin, C., and Kayalvizhi, G. (2005). What Do Pupils Think of Open Science Investigations? A Study of Singaporean Primary 6 Pupils. Educ. Res. 47 (1), 107-126. doi:10.1080/0013188042000337596

Chin, C., and Osborne, J. (2008). Students' Questions: A Potential Resource for Teaching and Learning Science. Stud. Sci. Edu. 44 (1), 1-39. doi:10.1080/ 03057260701828101

Ciardiello, A. V. (1998). Did You Ask a Good Question Today? Alternative Cognitive and Metacognitive Strategies. J. Adolesc. Adult Literacy 42, 210-219.

Craig, S. D., Gholson, B., Ventura, M., and Graesser, A. C., and the Tutoring Research Group (2000). Overhearing Dialogues and Monologues in Virtual Tutoring Sessions: Effects on Questioning and Vicarious Learning. Int. J. Artif. Intelligence Edu. 11, 242-253.

Dallas, D. (2006). Café Scientifique-Ddéjà Vu. Cell, 126(2), 227-229. doi:10.1016/ j.cell.2006.07.006

Dallas, D. (1999). Science in Culture. Nature 399 (6732), 120. doi:10.1038/20118

Davenport, J. R. A., Fouesneau, M., Grand, E., Hagen, A., Poppenhaeger, K., and Watkins, L. L. (2014). Studying Gender in Conference Talks - Data from the 223rd Meeting of the American Astronomical Society. arXiv [Preprint]. Available at: http://adsabs.harvard.edu/abs/2014arXiv1403.3091D.

Davies, S., McCallie, E., Simonsson, E., Lehr, J. L., and Duensing, S. (2009). Discussing Dialogue: Perspectives on the Value of Science Dialogue Events that Do Not Inform Policy. Public Underst Sci. 18 (3), 338-353. doi:10.1177/ 0963662507079760

De Jesus, H. P., Teixeira-Dias, J. J. C., and Watts, M. (2003). Questions of Chemistry. Int. J. Sci. Edu. 25 (8), 1015-1034. doi:10.1080/09500690305022

Derr, R. (1984). Questions: Definitions, Structure, and Classification. Reference Q. 24 (2), 186-190. Available at: www.jstor.org/stable/25827341.

Dijkstra, A. (2017). Analysing Dutch Science Cafés to Better Understand the Science-Society Relationship. Jcom 16, A03. doi:10.22323/2.16010203

Dijkstra, A. M., and Gutteling, J. M. (2012). Communicative Aspects of the PublicScience Relationship Explored. Sci. Commun. 34 (3), 363-391. doi:10.1177/ 1075547011417894

Dillon, J. T. (1998). “Theory and Practice of Student Questioning," in Strategic Help Seeking. Editor S. A. Karabenick (New York, NY: Routledge).

Driver, R. (1997). The Application of Science Education Theories: A Reply to Stephen P. Norris and Tone Kvernbekk. J. Res. Sci. Teach. 34 (10), 1007-1018. doi:10.1002/(sici)1098-2736(199712)34:10<1007::aid-tea3>3.0.co;2-v

Graesser, A. C., and McMahen, C. L. (1993). Anomalous Information Triggers Questions when Adults Solve Quantitative Problems and Comprehend Stories. J. Educ. Psychol. 85, 136-151. doi:10.1037/0022-0663.85.1.136

Graesser, A. C., and Olde, B. A. (2003). How Does One Know Whether a Person Understands a Device? the Quality of the Questions the Person Asks when the Device Breaks Down. J. Educ. Psychol. 95 (3), 524-536. doi:10.1037/0022-0663.95.3.524

Graesser, A. C., and Person, N. K. (1994). Question Asking During Tutoring. Am. Educ. Res. J. 31, 104-137. doi:10.3102/00028312031001104

Hinsley, A., Sutherland, W. J., and Johnston, A. (2017). Men Ask More Questions Than Women at a Scientific Conference. PLoS ONE 12 (10), e0185534. doi:10.1371/journal.pone.0185534

Hodson, D., and Hodson, J. (1998). From Constructivism to Social Constructivism: A Vygotskian Perspective on Teaching and Learning Science. Sch. Sci. Rev. 29 (289), 33-41.

Kerr, A., Cunningham-Burley, S., and Tutton, R. (2007). Shifting Subject Positions. Soc. Stud. Sci. 37 (3), 385-411. doi:10.1177/0306312706068492

Kim, I.-H., Anderson, R. C., Nguyen-Jahiel, K., and Archodidou, A. (2007). Discourse Patterns During Children's Collaborative Online Discussions. J. Learn. Sci. 16, 333-370. doi:10.1080/10508400701413419

Lehr, J. L., McCallie, E., Davies, S. R., Caron, B. R., Gammon, B., and Duensing, S. (2007). The Value of "Dialogue Events" as Sites of Learning: An Exploration of Research and Evaluation Frameworks. Int. J. Sci. Edu. 29 (12), 1467-1487. doi:10.1080/09500690701494092
L. W. Anderson and D. R. Krathwohl (Editors) (2001). A Taxonomy for Learning, Teaching, and Assessing: A Revision of Bloom's Taxonomy of Educational Objectives. Complete edition (New York, NY: Longman).

McCallie, E., Bell, L., Lohwater, T., Falk, J. H., Lehr, J. L., Lewenstein, B. V., et al. (2009). Many Experts, Many Audiences: Public Engagement with Science and Informal Science Education. A CAISE Inquiry Group Report. (Washington, DC: Center for Advancement of Informal Science Education). Available at: http:// caise.insci.org/uploads/docs/public_engagement_with_science.pdf.

Mejlgaard, N. (2009). The Trajectory of Scientific Citizenship in Denmark: Changing Balances Between Public Competence and Public Participation. Sci. Pub. Pol. 36 (6), 483-496. doi:10.3152/030234209X460962

Navid, E. L., and Einsiedel, E. F. (2012). Synthetic Biology in the Science Café: What Have We Learned About Public Engagement. Jcom 11 (04), A02. doi:10.22323/ 2.11040202

Ng, E., and Bereiter, C. (1991). Three Levels of Goal Orientation in Learning. J. Learn. Sci. 1 (3/4), 243-271. doi:10.1207/s15327809jls0103\&4_1

Norton, M., and Nohara, K. (2009). Science Cafés. Cross-Cultural Adaptation and Educational Applications. J. Sci. Commun. 08 (4), 1-11. doi:10.22323/2.08040201

Nussbaum, E. M. (2003). Appropriate Appropriation: Functionality of Student Arguments and Support Requests during Small-Group Classroom Discussions. J. Literacy Res. 34, 501-544. doi:10.1111/1467-9973.00273

Pizzini, E. L., and Shepardson, D. P. (1991). Student Questioning in the Presence of the Teacher During Problem Solving in Science. Sch. Sci. Math. 91, 348-352. doi:10.1111/j.1949-8594.1991.tb12118.x

Powell, M., and Lee Kleinman, D. (2008). Building Citizen Capacities for Participation in Nanotechnology Decision-Making: The Democratic Virtues of the Consensus Conference Model. Public Underst Sci. 17 (3), 329-348. doi:10.1177/0963662506068000

Ram, A. (1991). A Theory of Questions and Question Asking. J. Learn. Sci. 1 (3/4), 273-318. doi:10.1207/s15327809jls0103\&4_2

Rowe, G., and Frewer, L. J. (2005). A Typology of Public Engagement Mechanisms. Sci. Technol. Hum. Values 30 (2), 251-290. doi:10.1177/0162243904271724

Scardamalia, M., and Bereiter, C. (1992). Text-Based and Knowledge Based Questioning by Children. Cogn. Instruction 9, 177-199. doi:10.1207/ s1532690xci0903_1

Telis, N., Glassberg, E. C., Pritchard, J. K., and Gunter, C. (2019). Public Discussion Affects Question Asking at Academic Conferences. Am. J. Hum. Genet. 105, 189-197. doi:10.1016/j.ajhg.2019.06.004

Uwajeh, M. K. C. (1996). Is 'may I Ask You a Question?' a Question. Prag 6 (1), 89-109. doi:10.1075/prag.6.1.02uwa

Vygotsky, L. S. (1978). "Interaction Between Learning and Development," in Mind in Society: The Development of Higher Psychological Processes. Editors M. Cole, V. John-Steiner, S. Scribner, and E. Souberman (Cambridge, MA: Harvard University Press).

Watts, M., Gould, G., and Alsop, S. (1997). Questions of Understanding: Categorising Pupils' Questions in Science. Sch. Sci. Rev. 79 (286), 57-63.

Zorn, T. E., Roper, J., Weaver, C. K., and Rigby, C. (2012). Influence in Science Dialogue: Individual Attitude Changes as a Result of Dialogue Between Laypersons and Scientists. Public Underst Sci. 21 (7), 848-864. doi:10.1177/0963662510386292

Conflict of Interest: The authors declare that the research was conducted in the absence of any commercial or financial relationships that could be construed as a potential conflict of interest.

Publisher's Note: All claims expressed in this article are solely those of the authors and do not necessarily represent those of their affiliated organizations, or those of the publisher, the editors and the reviewers. Any product that may be evaluated in this article, or claim that may be made by its manufacturer, is not guaranteed or endorsed by the publisher.

Copyright $\odot 2021$ Nesseth, Henson and Barriault. This is an open-access article distributed under the terms of the Creative Commons Attribution License (CC BY). The use, distribution or reproduction in other forums is permitted, provided the original author(s) and the copyright owner(s) are credited and that the original publication in this journal is cited, in accordance with accepted academic practice. No use, distribution or reproduction is permitted which does not comply with these terms. 